\title{
The Effect of Leisure Satisfaction and Psychological Well-being among Screen Golf Participants
}

\author{
Jung Yun Jang \\ Researcher, Physical, Health and Arts Education, \\ Jeollanamdo Office of Education, Jeollanam-do, Korea \\ jungyunjang@korea.kr
}

\begin{abstract}
This study investigates leisure and psychological outcomes of screen golf, leisure satisfaction, and psychological well-being accessed from screen golf participants compared by gender, age, and perceived screen golf skill level. A total of 309 screen golfers $(209$ males and 100 females) completed the Korean version of the Leisure Satisfaction Scale and the CognitiveAffective States Scale for access to psychological well-being. The results indicated that there were no significant differences in leisure satisfaction and psychological well-being by screen golf participants' gender. Psychological well-being was different by age group and it was higher for participants in age 50s and older than for those age 40s and younger. However, there was no significant difference in age in leisure satisfaction. Lower-level screen golf score participants had higher leisure satisfaction and psychological well-being than higher-level screen golf score participants. Leisure satisfaction has a significant effect on psychological well-being. Based on the findings, participation in screen golf using virtual reality technology can lead to leisure satisfaction that can increase individual psychological well-being. Furthermore, screen golf offers improved accessibility or skills for low-skilled or novice golfers. The findings highlight that screen golf may be useful and attractive to recreational golf for both women and men, the elderly, and low-skilled screen golfers.
\end{abstract}

Keywords: Screen golf, Leisure satisfaction, Psychological well-being

\section{Introduction}

It is well documented that a physically active lifestyle is important for psychological wellbeing, health benefits, and improved quality of life [1][2]. Despite the benefits of physical activity for physical and psychological health, there are many obstacles to participation in physical activity during leisure time. The tendency toward doing physical activity during leisure time can be influenced by individual characteristics such as age, gender, social characteristics, social participation, and social networks [3]. Furthermore, physical and social environments are not only associated with physical activity, but also with motivation and opportunities to exercise [4].

Participation in PA as a leisure activity can be explained through the perspective of the Theory of Planned Behavior (TPB). TPB is one of the most valid theories for theoretical emphasis in the exercise/PA domain [1][5][6].

TPB has helped explain why people do certain leisure activities, and it is based on the belief that one's behavior is essentially dependent on intention [1]. According to Adjzen's TPB, three

Article history:

Received (April 15, 2021), Review Result (May 5, 2021), Accepted (July 10, 2021) 
principal hypotheses influence one's intention; attitude, subjective norm, and perceived behavioral control. Among these three constructs, an attitude refers to one's affective and instrumental attitude towards the behavior (e.g., enjoyable or wise), subjective norms signify one's injunctive and descriptive beliefs toward others concerning (e.g., approved by others), Perceived Behavioral Control (PBC) means one's behavior can be performed in terms of both self-efficacy and controllability (e.g., whether the task is easy or difficult to do, and whether the performers have little or great control).

In the PA field, researches show that TPB can predict PA behavior [7][8] and a meta-analytic study suggested that attitude and PBC predicted intention to perform PA [9]. Recently, researchers found that PBC is the strongest and significant construct of TPB toward intention to participate in regular PA and PA behavior [1]. Rhodes \& Mark [10] suggested that PBC refers to the "individual's perception of the ability that they have to perform a behavior, and it can involve barriers or facilitators to behavior as resources, skills, and opportunities (e.g., time, fatigue, weather, access to facilities, and money)." Based on previous research, they also suggested that having a high level of intention and PBC signify a greater likelihood of behavior.

Golf is one of the most interesting leisure sports to examine with the PBC concept. Golf is growing globally as a leisure activity; 50 million people are traveling to play on 32,000 golf courses around the world, and golf tourism is the largest sports-related travel market [11].

In Korea, even if an individual has a favorable attitude towards the sport, performing golf is not always possible due to constraints such as weather, time, space, economic conditions, and others (e. g. the availability of friends or playing partners). Interestingly, more than $50 \%$ of golf courses in the world are located in North America [12], which means there are a disproportionate number of golf courses in other areas such as Korea and Japan, which has caused a high cost per round for golf participation in Korea. For this reason, Koreans spend about 200,000 won (\$220) for a round of golf, and this high fee is one of the important reasons for the increasing popularity of golf tourism abroad. This imbalance has also led Korea to create the largest screen golf (or virtual golf) industry of any country. As an alternative to playing golf on a real course, screen golf has been broadly popularized as a part of the leisure culture among Koreans who are interested in golf. Screen golf can be located near to one's home or office, and it is to do this activity with others, to such an extent that it is compared to other easy social activities.

In the case of screen golf, 'reality' is the most essential difference from other video games. Most of all, people can practice and maintain their skills by swinging with real (or their own) golf clubs in screen golf without the leisure constraints of playing on a golf course. One of the advantages of screen golf is technological feedback regarding participants' performance. Furthermore, participants feel skill improvement and can develop strategies for golf matches through screen golf [13]. Also, golfers' concerns about the environment affect their intentions to play on a course [14]. This virtual practice can also help participants develop strategies for playing on real courses in the future.

The hypothesis of this study is that (1) leisure satisfaction and psychological well-being will vary by screen golf participants' gender, age, and screen golf level, (2) screen golfers' leisure satisfaction and psychological well-being will be positively related, and (3) screen golfers' leisure satisfaction will have a positive effect on psychological well-being. This will be the first investigation of the psychological benefits of screen golf in English documentation.

\section{Methods}

\subsection{Participants}


A convenience sampling was used to collect data from 309 screen golf participants consisting of 209 males $(67.6 \%)$ and 100 females (32.4\%) and varied in years of golf experience $(M=2.07$ years, $S D=.740)$ participated in this study. These participants ranged in age from 20 to 60 years old $(M=3.65, S D=1.05)$. Among the golf level of participants, $5(1.5 \%)$ were under $70,115(37.5 \%)$ were range from 80 to 90,99 (32\%) were range from 90 to 100, 88 (28.4\%) were range from 100 to 110. The survey was conducted in an urban area in Seoul (24.6\%), Gyeonggi-do (20.1\%), and Chungcheong-do (55.3\%) of South Korea.

\subsection{Measures}

Demographic Questionnaire Participants completed a brief demographic questionnaire that required participants to provide information about their golf participation, including gender, age, region, and screen golf level. For the screen golf level, participants answered an openended question about their perceived average screen golf score for an 18-hole round.

Leisure Satisfaction Scale (LSS) Validated Korean version of LSS [15] based on Beard and Ragheb [16] LSS has been used for access screen golf participants' leisure satisfaction. LSS is a 24-item, self-report measure that assesses psychological, educational, social, relaxation, physiological, and environmental or, more specifically, satisfaction, constructs. Responses are recorded on a 5-point Likert-type scale ranging from 1 (strongly disagree) to 5 (strongly agree). The LSS has been shown to have high internal consistency with alpha coefficients ranging from .86 to $.92[15]$.

Cognitive-Affective States Scale (CASS) Yang [17] developed CASS to measure Korean recreational sports participants' psychological well-being which suggested questions for measuring an individual's positive psychological state. The includes 20-item self-report inventory measures psychological well-being across four subscales, based on the conceptual definition of wellness associated with psychological well-being and related to the feeling of self-realization ( e.g., "I feel a greater sense of accomplishment than to participate in other activities"), self-confidence (e.g., "I feel proud of myself"), feeling of flow (e.g., "I am absorbed in the activity itself"), and hedonic enjoyment (e.g., "I feel very strong enjoyment"). Individuals responded on a 5-point Likert-type scale ranging from 1 (strongly disagree) to 5 (strongly agree). The CASS has been reported to have strong measures of reliability for the subscale's alpha coefficients .76 to .83 .

\subsection{Procedures}

A person in charge of screen golf facilities was contacted to request their cooperation for the present study. After securing the permission of the study, approval was obtained by the Association of Korean University Ethics Advisory Committee. For the survey, we contacted randomly chosen screen golf facilities in three metropolitan cities in Korea and obtained permission to collect data from 10 facilities. These screen golf clubs were located in the downtown areas of each city. A group of participants was given a brief explanation of the present study and those who agreed to volunteer for this survey completed the informed consent form and the questionnaires. The survey took approximately 15-20 minutes to complete.

\subsection{Data analysis}

Before the data analyses, the participants' data were verified by the researchers, after which the frequency, descriptive statistics, and Cronbach's alpha coefficients were calculated to describe the sample and examine the internal consistency of the self-report measures in this 
study. A one-way analysis of variance (ANOVA) was conducted to examine the participants' age, screen golf level, and the difference between leisure satisfaction and psychological wellbeing. Duncan's post hoc was used analyses for clarifying the difference by groups. Pearson correlations were used to examine the two-tailed correlations among the variables. Furthermore, regression analyses were performed to examine the predictive strength of participants' leisure satisfaction on psychological well-being. All statistics were performed using SPSS (version 18.0 for Windows, SPSS Inc., Chicago, IL). A prior level of significance was set at $p<.05$.

\section{Results}

With regards to the purpose of this study, the different gender, age, and golf level groups were compared with respect to leisure satisfaction and psychological well-being.

The independent $t$-test results revealed no significant differences in leisure satisfaction $(t=$ $-.050, p>.960)$ and psychological well-being $(t=1.286, p>.199)$ by screen golf participants' gender. Furthermore, an analysis of variance (ANOVA) was conducted to determine if the variance of leisure satisfaction and psychological well-being differed with regards to age. The ANOVA was significant in psychological well-being by age, $F(3,305)=3.798, p<.01, \eta^{2}=$ .037. As a result of post-hoc Duncan tests, it was revealed that psychological well-being was demonstrated by participants age 60 s and older $(M=4.21, S D=.39)$ and age 50s $(M=4.19, S D$ $=.37)$ more than those in their age 30s $(M=405, S D=.26)$ and age 40s $(M=4.06, S D=.35)$. There were no significant differences between age group on leisure satisfaction in [Table 1].

Table 1. Comparison of LS and PWB to age

\begin{tabular}{|c|c|c|c|c|c|}
\hline \multirow{2}{*}{ Age } & \multirow{2}{*}{ Variable } & \multirow{2}{*}{$M \pm S D$} & \multirow{2}{*}{$F$} & \multicolumn{2}{|c|}{$95 \% C I$} \\
\hline & & & & LO & $\mathrm{HI}$ \\
\hline $30(n=43)$ & \multirow{4}{*}{ LS } & $3.98 \pm .25$ & \multirow{4}{*}{.253} & 3.91 & 4.06 \\
\hline $40(n=78)$ & & $3.97 \pm .23$ & & 3.92 & 4.02 \\
\hline $50(n=121)$ & & $3.99 \pm .30$ & & 3.93 & 4.04 \\
\hline $60(n=67)$ & & $4.01 \pm .27$ & & 3.94 & 4.07 \\
\hline $30(n=43)$ & \multirow{4}{*}{ PWB } & $4.05 \pm .26$ & \multirow{4}{*}{$3.798^{* *}$} & 3.97 & 4.13 \\
\hline $40(n=78)$ & & $4.06 \pm .35$ & & 3.98 & 4.14 \\
\hline $50(n=121)$ & & $4.19 \pm .37$ & & 4.12 & 4.26 \\
\hline $60(n=67)$ & & $4.21 \pm .39$ & & 4.11 & 4.30 \\
\hline
\end{tabular}

[Table 2] demonstrates the comparison between all LS and PWB with perceived screen golf level. Specifically, the ANOVA results revealed significant differences in leisure satisfaction $(\mathrm{F} 2,306=11.414, \mathrm{p}<.001, \eta 2=.075)$ and psychological well-being $(\mathrm{F} 2,306=8.777, \mathrm{p}<$ $.001, \eta 2=.057$ ) by participants' screen golf level. However, the results of the post-hoc test were not significant.

Table 2. Comparison of LS and PWB to screen golf level

\begin{tabular}{|c|c|c|c|c|c|}
\hline \multirow{2}{*}{ Age } & Variable & \multirow{2}{*}{$M \pm S D$} & \multirow{2}{|c|}{$95 \% C I$} \\
\cline { 4 - 5 } & & & & LO & HI \\
\hline$<90(\mathrm{n}=122)$ & LS & $3.90 \pm .27$ & $11.414^{* * *}$ & 3.22 & 5.00 \\
\hline
\end{tabular}




\begin{tabular}{|c|c|c|c|c|c|}
\hline $90-100(n-99)$ & & $4.01 \pm .26$ & & 3.48 & 4.57 \\
\hline$>100(\mathrm{n}=88)$ & & $4.08 \pm .25$ & & 2.96 & 4.86 \\
\hline$<90(\mathrm{n}=122)$ & \multirow{3}{*}{ PWB } & $4.06 \pm .35$ & \multirow{3}{*}{$8.777^{* * *}$} & 3.42 & 5.00 \\
\hline $90-100(n-99)$ & & $4.13 \pm .35$ & & 3.17 & 4.83 \\
\hline$>100(\mathrm{n}=88)$ & & $4.27 \pm .36$ & & 3.00 & 4.92 \\
\hline
\end{tabular}

Before performing the simple regression analysis, significant correlations were identified among all the variables. The descriptive statistics of the variables are shown in [Table 3]. Specifically, leisure satisfaction was significantly related to psychological well-being, with values of $r=.46$. There were significant coefficients between leisure satisfaction on psychological well-being.

Table 3. Correlations among variables

\begin{tabular}{|c|c|c|c|c|}
\hline Variable & LS & PWB & M & SD \\
\hline LS & 1 & $(.61)$ & 3.99 & .27 \\
\hline PWB & $.46^{* *}$ & 1 & 4.14 & .36 \\
\hline$* * * p<.001$
\end{tabular}

As shown in [Table 4], the results revealed that leisure satisfactions were a positive predictor of psychological well-being, with $R^{2}=.212, F(1,307)=82.530, p<.001$.

Table 4. Regression analysis for variable prediction LS

\begin{tabular}{|c|c|c|c|c|}
\hline Variable & B & SE & $\beta$ & $t$ \\
\hline Constant & 1.695 & .270 & & $6.266^{* * * *}$ \\
\hline LS & 0614 & .068 & .460 & $9.085^{* * *}$ \\
\hline$* * * p<.001$
\end{tabular}

\section{Discussion}

This study aimed to investigate the leisure satisfaction and psychological well-being among screen golf participants and to explore the variables that are compared by gender, age, and perceived screen golf skill level.

The results of the present study showed that there was no difference in LS and PWB between male and female participants. This result can be interpreted as significant: unlike the general perception that men prefer participating in sports, the findings of this study might indicate that screen golf can be used to facilitate women's access to sports activities. In sport and leisure studies, women and girls are still considered to be affected by gender differences, and it is generally expected that male participants will show higher levels of motivation or participation, performance, and satisfaction than women. In terms of physical activity, women and girls create their self-fulfilling prophecy through erroneous beliefs such as the idea that they have lower abilities [18], and these beliefs are acting as constraints on participating in physical activity for women. In previous research, female professional golfers shared the opinion that women are more sensitive to the pressures of golf [19]. Traditionally, the focus of golf as a sport was on masculine nature. Nearly $80 \%$ of golf participants worldwide are men [20] and yet women's golf participation is still far behind that of men even as it is increasing [19]. Despite this suggestion about women's golf participation, the result of the present study suggests that gender might not be a significant constraint for achieving positive psychological benefits through 
participating in screen golf. These findings also reflect the possibility that screen golf can lead to increased potential participants or consumers in the golf industry.

Screen golf participants' LS were not significantly different and psychological well-being was higher for participants in age 50s and older than for those age 40s and younger. This indicates that participating in screen golf has a stronger effect on achieving positive psychological benefits for the older population. Similarly, previous studies of screen golf presented that the middle-aged and elderly participants gained satisfaction through screen golf activities [21]. Hayslip and Petrie [22] suggested that not only changes in cognition, anxiety, and coping, but also loss of flexibility was likely to influence older golfers' performance. Nevertheless, they discovered that with more than 1,300 participants in the world amateur golf championship, age did not moderate the effect of psychological skills or the direct predictor of golf performance in a golf competition. Based on those findings, they suggest that older golfers might successfully utilize psychological sports skills to minimize performance declines. In the same context, enjoying screen golf might lead to psychological benefits for all ages. Furthermore, the sport might have more positive influences on older participants. The younger population might not have enough social status to 'enjoy' leisure-time physical activity. According to the 2012 Survey of Citizen's Sport Participation in Korea, the participation in leisure activities and physical activities among people of ages 20-30 was less than among middle-aged and elderly populations, and the most frequent reason for participating less was 'not having enough time.'

The levels of skill in playing golf can be the critical reason to quit playing golf [19] and part of leisure constraint [23] among recreational golf participants. A game of golf might be a tough challenge for beginners. Following the results of this study, lower-level screen golf score participants had higher LS and PWB than higher-level screen golf score participants. As higher scores are more likely for those with a lower skilled level in this sport, these findings suggest that screen golf provides improvement of accessibility to (screen) golf games or skills for the lower-skilled or beginner golfers. In the same context, Son, et al [24] have found golfers with lower-level skills in the field felt more enjoyment when playing screen golf. Additionally, it is meaningful to have golf skill proficiency even among skilled level golfers, because screen golf includes motion analysis. Previous researchers suggested that developing skills and achievement from the successful performance are significant motivational factors of participating in screen golf [24].

Also found that skill acquisition is a factor of motivation that predicts the leisure satisfaction of screen golf. Those findings suggest that screen golf has high accessibility for everyone and that it is a quality alternative to participating in traditional golf for the increasing golfer population. It has previously been found that leisure satisfaction predicted psychological wellbeing and sports activities have a positive effect on the participant's psychological well-being [25][26][27].

According to the results of this study, screen golf participants' leisure satisfaction had a positive effect on psychological well-being. It has previously been found that leisure satisfaction predicted psychological well-being [28][29][30](e, g. Coleman \& Iso-Ahola, 1993; Sneegas, 1986; Wankel \& Berger, 1990). In particular, sports activities have a positive effect on the participant's psychological well-being [31]. Based on the findings in the present research, virtual reality technology might lead to leisure satisfaction, which would increase an individual's psychological well-being.

\section{Conclusion}


In summary, this study aims to investigate screen golf participants' leisure satisfaction and psychological well-being. These findings suggest that screen golf is a useful and attractive alternative to recreational golf for women and men, low-skilled golfers, and the elderly. Furthermore, screen golf participants' leisure satisfaction affects their psychological wellbeing. Based on this finding, screen golf may have a positive influence on enhancing psychological health. These results can also be a useful source to understand how and why screen golf had widespread popularity within Korea.

\section{References}

[1] S. Douglas, I. James, and C. Ballard, "Non-pharmacological interventions in dementia," Advances in Psychiatric Treatment, vol.10, no.3, pp.171-177, (2004) DOI:10.1192/apt.10.3.171

[2] L. J. Dodd, M. J. Forshaw, and T. Ward, "Predicting physical activity behavior in male and female young adults," International Journal of Sport Psychology, vol.43, pp.542-555, (2012)

[3] D. L. Gill, Y. K. Chang, K. M. Murphy, K. M. Speed, C. C. Hammond, E. A. Rodriguez, and Y. T. Shang, "Quality of life assessment for physical activity and health promotion," Applied research in quality of life, vol.6, no.2, pp.181-200, (2011) DOI: 10.1007/s11482-010-9126-2

[4] M. Lindstrom and M. Mohseni, "Social capital, political trust, and self-reported psychological health: A population-based study," Social Science and Medicine, vol.68, no.3, pp.436-443, (2009) DOI: 10.1016/j.socscimed.2008.11.004

[5] K. M. Leyden, "Social capital and the built environment: the importance of walkable neighborhoods," American Journal of Public Health, vol.93, no.9, pp.1546-1551, (2003) DOI: 10.2105/AJPH.93.9.1546

[6] I. Ajzen, "The theory of planned behavior," Organizational Behavior and Human Decision Processes, vol.50, no.2, pp.179-211, (1991) DOI: 10.1016/0749-5978(91)90020-T

[7] S. J. Biddle and C. R. Nigg, "Theories of exercise behavior," International Journal of Sport Psychology, vol.31, no.2, pp.290-304, (2000)

[8] I. Ajzen and B. L. Driver, "Application of the theory of planned behavior to leisure choice," Journal of Leisure Research, vol.24, no.3, pp.207-224, (1992) DOI: 10.1080/00222216.1992.11969889

[9] A. Pierro, L. Mannetti, L, and S. Livi, "Self-identity and the theory of planned behavior in the prediction of health behavior and leisure activity, self and identity," vol.2, no.1, pp.47-60, (2003) DOI: $10.1080 / 15298860309024$

[10] D. S. Downs and H. A. Hausenblas, "The theories of reasoned action and planned behavior applied to exercise: A meta-analytic update," Journal of Physical Activity and Health, vol.2, no.1, pp.76-97, (2005) DOI: 10.1123/jpah.2.1.76

[11] R. E. Rhodes, R. Mark, and E. O. Acevedo, "Social cognitive theories," The Oxford Handbook of Exercise Psychology, pp.273-294, (2012)

[12] R. Shipway, “Golf tourism,” Annals of Tourism Research, vol.39, no.3, pp.1731-1732, (2011)

[13] H. Briassoulis, "Sorry golfers, this is not your spot: Exploring public opposition to golf development," Journal of Sport and Social Issues, vol.34, no.3, pp.288-311, (2010) DOI: 10.1177/0193723510377314

[14] Y. C. Chung and M. J. Lyu, "Screen golf scenario for improvement of life skills," Korean Journal of Sport Psychology, vol.20, no.4, pp.43-60, (2009)

[15] H. Han, J. Hwang, and D. P. Woods, "Choosing virtual-rather than real-leisure activities: An examination of the decision-making process in screen-golf participants," Asia Pacific Journal of Tourism Research, vol.19, no.4, pp.428-450, (2014)

[16] J. K. Lee, "The contribution of participation in sport and exercise programs to life satisfaction of adults," $\mathrm{Ph}$. D. Seoul National University, Seoul, (1992) 
The Effect of Leisure Satisfaction and Psychological Well-being among Screen Golf Participants

[17] J. G. Beard and M. G. Ragheb, "Measuring leisure satisfaction," Journal of Leisure Research, vol.12. no.1, pp.20-33, (1980) DOI: 10.1080/00222216.1980.11969416

[18] M. H. Yang, "The effects of loyalty to sports activity on psychological well-being components in teachers," Journal of Korean Society for the Study of Physical Education, vol.4, no.2, pp.182-200, (2000)

[19] B. L. Fredrickson and K. Harrison, “Throwing like a girl: Self-objectification predicts adolescent girls' motor performance," Journal of Sport and Social Issues, vol.29, no.1, pp.79-101, (2005) DOI: $10.1177 / 0193723504269878$

[20] L. P. McGinnis and J. W. Gentry, "Getting past the red tees: Constraint's women face in golf and strategies to help them stay," Journal of Sport Management, vol,20, no.2, pp.218-247, (2006) DOI: 10.1123/jsm.20.2.218

[21] H. Reis and A. Correia, "Gender asymmetries in golf participation," Journal of Hospitality Marketing and Management, vol.22, no.1, pp.67-91, (2013)

[22] W. J. Shin, "The influence of motivation on leisure satisfaction of screen golf Users," M.D., Yong-In University, Kyung-ki, (2011)

[23] B. Hayslip Jr. and T. A. Petrie, "Age, psychological skills, and golf performance: A prospective investigation," Journals of Gerontology Series B: Psychological Sciences and Social Sciences, vol.69, no.2, pp.245-249, (2014) DOI: 10.1093/geronb/gbt010

[24] J. Jun and G. T. Kyle, "Understanding the role of identity in the constraint negotiation process," Leisure Sciences, vol.33, no.4, pp.309-331, (2011) DOI: 10.1080/01490400.2011.583157

[25] W. Son, S. M. Yoon, and S. M. Kim, "The effect of participation factors (enjoyment, education, help, and practicality) of them participated in screen golf on the intent of exercise adherence index," Journal of Sport and Leisure Studies, vol., no.43, pp.101-110, (2011) DOI: 10.51979/KSSLS.2011.02.43.101

[26] S. Z. F. O. E. Yapan and U. Öğrencilerinin, "An analysis of life satisfaction, psychological well-being and leisure satisfaction in university students doing exercise as a leisure activity," Social Mentality and Researcher Thinkers Journal, vol.6, no.28, pp.211-216, (2020) DOI: 10.31576/smryj.437

[27] E. Eskiler, Y. Yildiz, and C. Ayhan, "The effect of leisure benefits on leisure satisfaction: Extreme sports," Turkish Journal of Sport and Exercise, vol.21, no.1, pp.16-20, (2019) DOI: 10.15314/tsed.522984

[28] J. Li, C. C. Hsu, and C. T. Lin, "Leisure participation behavior and psychological well-being of elderly adults: An empirical study of Tai Chi Chuan in China," International Journal of Environmental Research and Public Health, vol.16, no.18, pp.3387, (2019) DOI: 10.3390/ijerph16183387

[29] D. Coleman and S. E. Iso-Ahola, "Leisure and health: The role of social support and self-determination," Journal of Leisure Research, vol.25, no.2, pp.111-128, (1993) DOI: 10.1080/00222216.1993.11969913

[30] J. J. Sneegas, "Components of life satisfaction in middle and later life adults: Perceived social competence, leisure participation, and leisure satisfaction,” Journal of Leisure Research, vol.18, no.4, pp.248-258, (1986) DOI: 10.1080/00222216.1986.11969663

[31] L. M. Wankel and B. G. Berger, "The psychological and social benefits of sport and physical activity," Journal of Leisure Research, vol.22, no.2, pp.167-182, (1990) DOI: 10.1080/00222216.1990.11969823

[32] Y. Netz, M. J. Wu, B. J. Becker, and G. Tenenbaum, "Physical activity and psychological well-being in advanced age: A meta-analysis of intervention studies," Psychology and aging, vol.20, no.2, pp.272-284, (2005) DOI: $10.1037 / 0882-7974.20 .2 .272$ 